\title{
A population - based study on Awareness of Cardiovascular Disease Risk Factors
}

\author{
"Chinju George and G. Andhuvan \\ Department of Pharmacy Practice PSG College of Pharmacy, Coimbatore- 641004
}

\begin{abstract}
Objective: The study was to assess the level of Knowledge and Awareness of Cardiovascular Disease Risk Factors in a selected population. Materials and Methods: Population - based study was carried out in people above 30 years of age. Heart Disease Fact Questionnaire (HDFQ) was used to assess the level of knowledge and awareness of risk factors during face- to -face interview with the participants. Results: The percentage of participants who were aware about risk factors were $48 \%$ and $52 \%$ were unaware. Among risk factors, Over weight was ranked as the most common, followed by high cholesterol level (98\%), high blood pressure (94\%) and Smoking (92\%). The participants were also aware about regular physical activity and exercise to lower risk factors for the heart disease. Conclusion: This study revealed the need for increasing awareness among the population utilizing community based education programs.
\end{abstract}

Keywords: Cardiovascular disease, risk factors, knowledge, awareness.

\section{INTRODUCTION}

Cardiovascular diseases (CVDs) are group of disorders of heart and blood vessels. According to WHO, heart disease especially coronary heart disease is the leading cause of death globally and one of the major health burdens worldwide. It has been predicted that these diseases will increase rapidly in India and this country will be host to more than half the cases of heart disease in the world. ${ }^{1}$

WHO noted that CVD has no geographic, socioeconomic or sex boundaries. It is estimated that far from being confined to the most developed countries, cardiovascular disease is the leading cause of death in developing countries as well. $80 \%$ of CVD death is contributed by countries with low and middle income.
Some people are at greater risk of cardiovascular disease than others. Factors linked to an increased risk of CVD are family history, age, sex, cigarette smoking, excessive alcohol consumption, abnormal lipid and lipoproteins, high blood pressure, high blood glucose, physical inactivity, Overweight and Obesity. $^{2}$

It is estimated that 23.3 million people will die by 2030 , because of cardiovascular disease. high blood pressure, high cholesterol level, high Blood glucose level, smoking, obesity and physical inactivity are conventional risk factors. ${ }^{3}$ Although cardiovascular disease occurs in the middle age or later, risk factors (smoking, dietary factors etc) are determined to great extend by behaviors learnt in childhood and continued to adulthood. 4
Submitted Date : 28-01-2014 Accepted Date : 22-05-2014

DOI: $10.5530 /$ ijopp.7.2.5

Address for correspondence: Dr. Chinju George Department of Pharmacy Practice, PSG College of Pharmacy, Peelamedu, Coimbatore - 641004, Tamil Nadu, India Mobile: 8754183241 E-mail: chinjugeorge143@ gmail.com

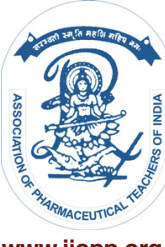

www.ijopp.org 
Adherence to healthy nutritional and lifestyle recommendations can play an essential role in the prevention of CVD. ${ }^{5}$ In order to encourage people to adopt a cardio protective lifestyle; little is known about knowledge of cardiovascular risk factors in general population. Knowledge is an essential step in developing a more cardio protective lifestyle. ${ }^{6}$ Socioeconomic indicator "education" is a strong predictor of cardiovascular risk factor knowledge. Higher knowledge is associated with higher education. Socioeconomic polarization could partly explain the fact that a low socioeconomic position has been associated with higher morbidity and mortality of chronic diseases ${ }^{7}$

\section{MATERIAL AND METHODS}

\section{Study design and Sample}

A Prospective study was carried out in a randomly selected population for a month in a Multispecialty Hospital. The study was to assess their knowledge regarding Cardiovascular Disease Risk Factors. Individuals who did not have a Communication Problem and perception problem (dementia, Schizophrenia) were included in the study. A total of 50 participants who met the eligible criteria were selected and interviewed face -to -face using HDFQ Questionnaire.

\section{RESULTS AND DISCUSSION}

50 participants were included in the study, $30(60 \%)$ male and $20(40 \%)$ female within $30-70$ years of age, over a period of one month.

This study was carried out to evaluate the Knowledge of risk factors for cardiovascular disease among the adult population. Based on Heart Disease Fact Questionnaire (HDFQ) Questionnaire, $48 \%$ of participants were able to acquire a score of 20 and above from a total of 25 , where as $52 \%$ of participants scored below 20 .

Overweight was considered as a major risk factor $(100 \%)$ for heart disease by the participants followed by high cholesterol level (98\%) ,High blood pressure level $(94 \%)$ and Smoking (92\%).

Few participants were unaware of older age being a greater risk factor $(10 \%)$ while some participants did not know family history of heart disease $(32 \%)$, diabetes as co-morbidity $(20 \%)$ as risk factors. $66 \%$ knew that male diabetic patients are at higher risk when compared to female diabetic patients. Regular physical activity $(90 \%)$ and exercising at gym $(92 \%)$ were considered as factors that help lower chances of developing heart disease, by the participants.

\begin{tabular}{lcc} 
Table 1: Demographic Characteristics & & \\
\hline Characteristics & $\mathbf{n}$ & $\%$ \\
\hline Age & 16 & 32 \\
$30-39$ & 17 & 34 \\
$40-49$ & 14 & 28 \\
$50-59$ & 3 & 6 \\
$60-69$ & & \\
Gender & 30 & 60 \\
Male & 20 & 40 \\
Female & & \\
Education & 27 & 54 \\
Lower than High School & 23 & 46 \\
High School or beyond & & \\
Occupation & & \\
Currently employed & 28 & 56 \\
Unemployed & 22 & 44 \\
Residence & & \\
Rural & & \\
Urban & 34 & 68 \\
\hline
\end{tabular}

\section{CONCLUSION}

In this study, half of the participants were fairly aware of the cardiovascular risk factors. Smoking, high blood pressure, hyperlipidemia and obesity as risk factors were known to most of the participants. The main finding of the study is that the majority of the populations were unaware about the association of risk factors such as age and family history with cardiovascular disease when in fact these risk factors are early predictors for the same. Only few participants knew that patients with diabetes have low HDL cholesterol and male diabetic patients are at higher risk when compared to female. The study calls for the importance of educating the population about the various risk factors especially age, 
Table 2: Correctly answered questions from the Heart Disease Fact Questionnaire

\begin{tabular}{lcc} 
Question & $\mathbf{n}$ & $\%$ \\
\hline Smoking is a risk factor for Heart disease & 46 & $92 \%$ \\
High Blood pressure is a risk factor for Heart Disease & 47 & $94 \%$ \\
High cholesterol is a risk factor for developing Heart disease & 49 & $98 \%$ \\
Being overweight increases a person's risk for Heart disease & 50 & $100 \%$ \\
Regular Physical activity will person's chance of getting Heart disease & 45 & $90 \%$ \\
Only exercising at a gym or in a class will help lower a person's chance of developing heart disease & 46 & $92 \%$ \\
\hline
\end{tabular}

\section{Table 3: Incorrectly answered questions from Heart Disease Fact Questionnaire}

\section{Question}

The older a person is ,the greater the risk of having Heart disease

If you have a family history of heart disease you are at a risk for developing heart disease

People with diabetes tend to have low HDL Cholesterol

Men with diabetes have a higher risk than women with diabetes

n

5

16

10

33
$\%$

$10 \%$

$32 \%$

$20 \%$

$66 \%$ family history and co-morbid conditions to prevent cardiovascular diseases as well as improve the quality of life of people with heart disease.

\section{ACKNOWLEDGEMENTS}

I would like to express my sincere gratitude to the Department of Pharmacy Practice, PSG Institute of Medical Science and Research Centre, for providing me an opportunity for conducting this research.

\section{REFERENCES}

1. WHO. Cardiovascular diseases [internet].2013[updated 2013 march; cited2013 June 7]. Available from: http://www.who.int/mediacentre/ factsheets/fs317//en/index.html.

2. Heart foundation of Australia: Risk factors for heart disease online resources [internet].2002 [updated 2004 Jul; cited 2010 Jun 3]. Available from: http:// www.nevdgp.org.au/info/heartf/school/risk.htm.
3. Sania Nishtar. Prevention of coronary heart disease in South Asia. The Lancet.2002: September 28; Vol.360:1015-1018.

4. World Health Organization. Cardiovascular diseases: Risk factors starts in childhood and youth online cvd atlas [internet].2002 [updated 2004; cited 2010 Jun 3]. Available from: http://www.who.int/cardiovascular diseases/en/ cvd atlas 04 childhood youth.pdf.

5. Patrick Mullie, Peter Clarys. Association between cardiovascular disease risk factor knowledge and life style. Food and Nutrition Sciences. 2011; (2): 1048-153.

6. Louise. Potvin, Lucie. Richard and Alison C. Edwards. Knowledge of Cardiovascular Disease Risk Factors among the Canadian Population: Relationships with Indicators of Socioeconomic Status. Canadian Medical Association Journal. 2000:May 2;Vol.162(9 suppl):S5-S11

7. Elizabeth B. Lynch, Kiang. Liu, Catarina I. Kiefe and Philip Greenland. Cardiovascular Disease Risk Factor Knowledge in Young Adults and 10-Year Change in Risk Factors: The Coronary Artery Risk Development in Young Adults (CAR-DIA) Study. American Journal of Epidemiology. 2006: October 12; Vol. 164 (No. 12): 1171-179. 